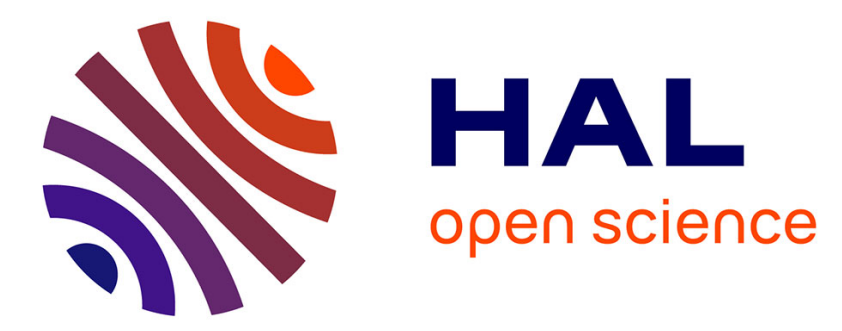

\title{
The Power of the Presidency in EU Council Decision-making
}

Jelmer Schalk, René Torenvlied, Jeroen Weesie, Frans Stokman

\section{To cite this version:}

Jelmer Schalk, René Torenvlied, Jeroen Weesie, Frans Stokman. The Power of the Presidency in EU Council Decision-making. European Union Politics, 2007, 8 (2), pp.229-250. 10.1177/1465116507076431 . hal-00571744

HAL Id: hal-00571744

https://hal.science/hal-00571744

Submitted on 1 Mar 2011

HAL is a multi-disciplinary open access archive for the deposit and dissemination of scientific research documents, whether they are published or not. The documents may come from teaching and research institutions in France or abroad, or from public or private research centers.
L'archive ouverte pluridisciplinaire HAL, est destinée au dépôt et à la diffusion de documents scientifiques de niveau recherche, publiés ou non, émanant des établissements d'enseignement et de recherche français ou étrangers, des laboratoires publics ou privés. 


\section{EUP}

European Union Politics

DOI: $10.1177 / 1465116507076431$

Volume 8 (2): 229-250

Copyright@ 2007

SAGE Publications

Los Angeles, London, New Delhi and Singapore

KEY WORDS

- EU decision-making

- EU presidency

- power

\section{The Power of the} Presidency in EU Council Decision-making

\section{Jelmer Schalk}

Utrecht University, The Netherlands

René Torenvlied

Utrecht University, The Netherlands

\section{Jeroen Weesie}

Utrecht University, The Netherlands

\section{Frans Stokman}

University of Groningen, The Netherlands

\section{ABSTRACT}

Research on the presidency of the EU shows mixed results. Although most scholars agree that the EU presidency is not able to advance its domestic interests in the European forum, Tallberg (2006) provides evidence for presidency effects. In the present paper, we empirically estimate presidency-based power in the Council of the European Union on the DEU data - a large-scale data set containing EU policy issues from various policy areas. We show that holding the presidency does significantly and positively contribute to the bargaining power of member states, but only in the final stages of decision-making. 


\section{Introduction}

The academic debate on who is powerful in Brussels concentrates on the relative impact of the European Commission, the European Parliament (EP) and the Council of the European Union (e.g. Tsebelis and Garrett, 2000; Selck and Steunenberg, 2004) and the impact of member states on policy outcomes (Bindseil and Hantke, 1997; Lootsma, 2004). Most scholars agree that the Council is the most powerful among the three governmental institutions of the European Union (EU) (Westlake, 1995; Cini, 1996; Hayes-Renshaw and Wallace, 1997). At face value, one would thus expect the presidency of the Council to have additional leverage in EU policy-making. Nevertheless, the scarce literature addressing the power of the EU presidency suggests that member states at the helm cannot exert more influence, or even have less influence, compared with other member states (Schout, 1998).

Officially, the presidency is expected to be impartial (Tallberg, 2006). Accordingly, the literature emphasizes the presidency's role as a neutral broker and negotiation facilitator. Although authors recognize that member states holding the presidency pursue their domestic agendas, the degree of their success is considered to be low (Bassompierre, 1988; Westlake, 1995; Cini, 1996; Hayes-Renshaw and Wallace, 1997; Sherrington, 2000). Several arguments sustain this view. First, the relatively short period at the helm narrows the scope of what can be done. Since a member state is chair for only six months and the bargaining process is slow, only a limited number of domestic objectives can be pursued. ${ }^{1}$ Second, the lion's share of the presidency's time and resources are spent on administrative tasks - the ongoing Council business. These tasks are not directly related to influencing policy outcomes (Kirchner, 1992). Third, the presidency is often faced with external events that require immediate attention. Fourth, the presidency is hampered by policy inheritance: policies that have been set out prior to a member state's presidency term are hard to reverse. Fifth, the formal powers of the presidency, in terms of agenda-setting and veto power, are limited.

A final reason for a toothless presidency is the existing 'culture of consensus' (Van Schendelen, 1996; Mattila and Lane, 2001). Indeed, decisionmaking in the European Union is often characterized by intensive negotiations and compromises (Sherrington, 2000; Thomson et al., 2006). A culture of consensus constrains presidency behaviour, because other member states will keep it to its expected neutrality and its role as a welder of integrationist policy solutions. Thus, presidencies may be forced to spend resources to further Community interests and strengthen their reputation.

One author challenges the well-established view of the toothless presidency. Tallberg (2006) develops a theory of formal leadership and presidency 
power, grounded in rational choice institutionalism (Shepsle, 1989; Aspinwall and Schneider, 2000). His main thesis is that the rules, norms and procedures that constitute the institutional framework provide the presidency with asymmetric access to information and asymmetric control over the negotiation procedure vis-à-vis other member states. These advantages can and will be brought into play, not only to ensure efficient EU bargaining, but also to advance the presidency's domestic interests. Tallberg (2006) relies on descriptive case studies to support his argument.

In this article we will try to shed some light on the puzzle of presidency power. We study the ability of individual member states to influence policy outcomes. We aim at finding out whether member states holding the presidency can exert more influence on policy outcomes than expected on the basis of their formal voting power. By recognizing that the bargaining process in the EU is a relay race - it typically involves multiple presidencies that hand over leadership over the negotiations every six months - we try to locate the stage in the bargaining process where presidency power is largest.

We apply a cooperative bargaining model and estimate parameters for presidential bargaining strength using the 'Decision making in the European Union' (DEU) data set (see Thomson et al., 2006). This data set consists of 162 controversial policy issues, nested in 66 Commission proposals. The issues are selected over various policy areas, such as Agriculture and the Internal Market, and subject to either qualified majority voting (QMV) or unanimity under the co-decision and consultation procedures. The large number of cases used in the data set allows for more general conclusions about presidency power than has previously been possible.

\section{Presidency power in different stages of involvement}

EU bargaining is a complex process. Before policy proposals become legislation, they go back and forth between the Commission, the Council and the Parliament, which can amend, reject, delay and accept proposals under different institutional procedures and decision rules (Hix, 2005: 100-1; Wallace and Wallace, 2000: 11-22). It follows that bargaining over a policy proposal is a time-consuming and path-dependent process, involving multiple presidencies. Hence, we propose a stage model of the EU bargaining process that allows us to discriminate between the different mechanisms behind presidency power. The stage model distinguishes between four stages of presidency involvement, based on two important events in EU decisionmaking: (a) the adoption of a Commission proposal, and (b) the formal decision of the Council. 
A schematic representation of the bargaining process is presented in Figure 1. The stages represent four intervals that may overlap: for any proposal, the date of adoption and date of the final decision are known, and presidencies are backwardly assigned to intervals around these two reference points. $^{2}$ Except for the intermediate presidency stage (I), each interval is maximally six months and involves one presidency. The pre-adoption stage (PA) defines the presidency that was in office before the presidency under which the Commission adopted a proposal. The latter is the adoption stage (A) presidency. Subsequent intermediate stage presidencies (I) have their term(s) between stage A and the final voting stage (D). The presidency in stage $\mathrm{D}$ reaches a final decision in the Council.

We distinguish between two key processes that may yield additional powers to presidencies. The first process concerns the decentralized negotiations in the Committee of Permanent Representatives (COREPER) and the Commission during agenda-setting and the adoption of Commission proposals. The second process is centralized bargaining among ministers in the Council during the voting stage. When presidencies have a specific advantage in both processes over other member states to further their domestic goals, the following hypothesis holds.

Hypothesis 1 (Presidency Effect Hypothesis): Member states holding the presidency are better able than other member states to realize policy outcomes close to their policy position.

We now briefly discuss the mechanisms that could account for the additional power of presidencies in decentralized agenda-setting, centralized bargaining and voting. With respect to decentralized agenda-setting, Tallberg $(2003,2006)$ argues that Presidents are formal leaders in the European Union and able to manage the policy agenda. He distinguishes between three

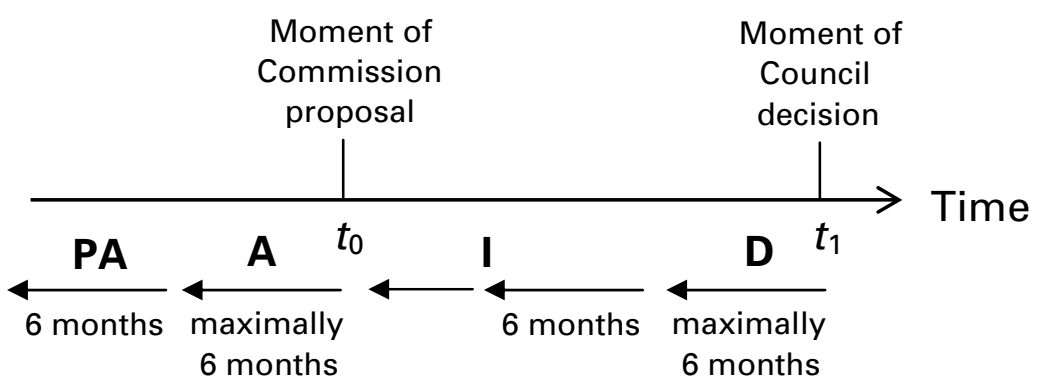

Figure 1 Stages of presidency involvement in the EU bargaining process. Notes: $\mathrm{PA}=$ pre-adoption stage; $\mathrm{A}=$ adoption stage; $\mathrm{I}=$ intermediate stage; $\mathrm{D}=$ voting stage. 
categories of agenda management: agenda-setting, agenda-structuring and agenda exclusion (Tallberg, 2003). Agenda-setting refers to the right to initiate proposals. Although formal agenda-setting power in the EU lies with the Commission, Tallberg argues that the presidency can: (1) raise awareness of problems, and convince the Commission to take action, (2) develop specific proposals for action, and (3) develop policy initiatives in areas where actor configurations are as yet unclear or undefined - for example by drawing up a 'Presidency program' (Tallberg, 2003: 7). By adopting a proposal close to the President's position, the Commission maximizes the probability that a proposal will pass, because the presidency is likely not only to put it on the agenda but also to devote more resources to striking a bargain. Lobbying efforts may thus induce the Commission to adopt proposals that are favourable to the presidency. If these mechanisms are at work, the following hypothesis holds.

Hypothesis 2 (Adoption Stage Presidency Hypothesis): The member state that holds the presidency in the adoption stage is better able to realize a policy outcome close to its policy position than are member states that hold the presidency in the preceding pre-adoption stage and member states that hold the presidency in the subsequent intermediate stage.

With respect to centralized bargaining in the Council, the presidency is able to structure the agenda of Council meetings. In these meetings, the issues that underlie policy proposals adopted by the Commission are discussed. The presidency determines the sequence in which proposals and issues are discussed and the methods of decision-making, such as competing proposals versus single negotiation texts (Tallberg, 2003). In addition, the presidency determines the frequency of Council meetings. Finally, the presidency has the right to exclude unfavourable proposals from the Council agenda - at least for its period at the helm.

In addition to agenda management, the presidency takes the initiative in proposing compromise solutions to the Council, i.e. amendments of, or alternatives to, the Commission proposal - the so-called 'Presidency compromise' (Hayes-Renshaw and Wallace, 1997; Nicoll, 1998; Tallberg, 2006). It is reasonable to assume that the presidency will propose among those possible compromise solutions the one closest to its own policy position. These mechanisms would lead to the following hypothesis.

Hypothesis 3 (Voting Stage Presidency Hypothesis): Member states that hold the presidency in the voting stage are better able to realize a policy outcome close to their policy position than are member states that hold the presidency in the intermediate stage. 


\section{A cooperative bargaining model of Council decision-making}

Policy outcomes depend on the nature of the bargaining process. We assume that cooperative bargaining takes place in the Council. Cooperative bargaining may be promoted by the existence of highly inclusive voting rules. Decisions are often taken unanimously, even when only a qualified majority is needed (Mattila and Lane, 2001; Thomson et al., 2006). The norm of consensus is strong among actors in the European Union. Inclusive voting rules and a long shadow of the future could result in tough, non-cooperative bargaining (Fearon, 1988; Scharpf, 1988). However, if these rules are combined with the existence of a threat point that is undesirable to all member states, these member states have a strong incentive to cooperate (Achen, 2006). The existence of an undesirable threat point has been found consistently in case studies (Hayes-Renshaw and Wallace, 1997). Finally, cooperative bargaining models are better suited to study decision-making situations that are highly informal and complex (Achen, 2006: 97). ${ }^{3}$

Collective decision-making in the European Union is assumed to concentrate on a set of policy proposals. These are negotiation texts adopted by the European Commission, which address a certain topic in a certain policy area. Each proposal comprises $j$ policy issues $(j=1,2, \ldots, n)$. Each issue consists of a set of policy alternatives $X_{j}$. A policy alternative of issue $j$ is denoted by $a_{j}\left(a_{j}=1_{j}, 2_{j}, \ldots, v_{j}\right)$, where $v_{j}$ is the number of alternatives of issue $j$. As is the case in many spatial models of decision-making (e.g. Crombez, 2000), it is assumed that these policy alternatives can be ordered on a single dimension. In our case, each alternative falls in the interval $[0,100]$, as a point on a one-dimensional policy scale. Variable $x_{j} \in[0,100]$ is a policy scale variable, representing the values of issue $j$ 's policy alternatives.

We apply the model to the period 1999-2001, before the accession of 10 new member states. Hence, the actors include 15 member states, the European Commission and the European Parliament, denoted by $i(i=1,2, \ldots, 17)$. These actors take policy positions on each issue $j$, which is the policy alternative initially most preferred and expressed just after the adoption of a proposal by the European Commission. The policy positions of actors $i$ on issues $j$ are denoted by $x_{i j} \in X_{j}$ and are points on the policy scale. Actors are assumed to behave rationally and negotiate a policy outcome as close to their policy position as possible. The policy outcome is denoted by $O_{j}$, where $O_{j} \in X_{j}$. The utility functions of the actors are assumed to be single-peaked and monotonically decreasing, which means that the larger the distance between the outcome and the initially preferred policy position, the more utility loss an actor experiences.

The final policy outcome is supposed to depend on (1) the power of actors, (2) their salience and (3) the nature of the bargaining process. In this analysis, 
power is defined as the sum of resources that can be used by an actor to move the policy outcome on an issue towards the desired outcome. The power of actor $i$ on issue $j$ is denoted by $w_{i j} \in[0,1]$. Power plays a central role here, for it is on this concept that we evaluate the presidency against other member states. The basic idea is that the institutional features associated with the presidency may constitute power resources additional to those usually identified, such as formal voting power, reputation and expertise (Torenvlied, 2000; Bailer, 2004).

The policy outcome will also depend on the relative salience a member state attaches to different issues. Given the limited amount of time and resources that can be spent on gathering information and bargaining, member states assign different priorities to issues. Salience is the fraction of the power a member state is willing to utilize to bring the policy outcome closer to its preferred position (Bueno de Mesquita and Stokman, 1994; Arregui et al., 2004). The salience of actor $i$ on issue $j$ is denoted by $s_{i j} \in[0,100]$.

The cooperative bargaining model we apply is a weighted version of the mean voter model (Caplin and Nalebuff, 1991). The general underlying assumption of the model is that all actors are willing to shift their positions to a policy outcome that takes all their divergent interests into account. The mean policy position weighted by actors' power and salience is a first-order approximation of the Nash bargaining solution (NBS) in cooperative game theory (Nash, 1950). ${ }^{4}$ This is true only when the threat point - the policy outcome that prevails when no agreement is reached - is far less desirable than any outcome for all member states (Achen, 2006). The NBS predicts Pareto-optimal outcomes on one-dimensional issues by maximizing the product of the actors' quadratic utility functions.

The weighted mean voter model in equation (1) predicts the outcome on issue $j\left(O_{j}\right)$ by the mean of the positions $\left(x_{i j}\right)$ of all actors, weighted by the product of their power $\left(w_{i j}\right)$ and salience $\left(s_{i j}\right)$ (Van den Bos, 1991):

$$
O_{j}=\frac{\sum_{i=1}^{17} x_{i j} s_{i j} w_{i j}}{\sum_{i=1}^{17} s_{i j} w_{i j}}
$$

\section{Testing for presidency power}

A starting point for analysing the power of the presidency is the impact the presidency has on the outcomes of cooperative bargaining. Since we wish to investigate the presidency's power to advance domestic interests, a member state's power should be made conditional upon whether or not it holds the presidency on an issue. We model this by multiplying $w_{i j}$ by a scale factor $\alpha_{i j}$ 
when member state $i$ holds the presidency, and retain $w_{i j}$ as the power score when member state $i$ does not hold the presidency. Scale factor $\alpha_{i j}$ represents additional power $\left(\alpha_{i j}>1\right)$ or reduction in power $\left(\alpha_{i j}<1\right)$ owing to the presidency. We will present different models for $\alpha_{i j}$ that differ by the explanatory variables entered in a log-linear model for alpha. A few examples are discussed below. To test the presidency effect hypothesis (H1), we include only one unknown parameter $\beta$ for a dummy variable that indicates whether or not a member state holds the presidency in the bargaining process. Values for all other variables in the model are known, including the outcome $O_{j}$. If positive, $\beta$ indicates that member states holding the presidency have the ability to realize policy outcomes close to their policy position in addition to the power they would exercise when they do not hold the presidency. A negative sign of $\beta$ indicates that the power of member states is reduced during their presidency term. Hence, $\beta$ is an overall measure of presidency power. Because negative power has no clear interpretation and member states will not harm their interests without clear reasons, we assume that $w_{i j}$ is not negative. Thus, we carry out a logistic transformation on $\alpha$ and obtain the following model in equation (2):

where:

$$
O_{j}=\frac{\sum_{i=1}^{17} x_{i j} s_{i j} w_{i j} a_{i j}}{\sum_{i=1}^{17} s_{i j} w_{i j} a_{i j}}+e_{j}
$$

$\log \left(\alpha_{i j}\right)=\beta P_{i j}$

$P_{i j}=1$ if member state $i$ holds the presidency on issue $j ; P_{i j}=0$ otherwise.

Two interpretable results follow from this model. First, if the presidency is influential, this model should lead to more accurate predictions of the policy outcomes than the weighted mean voter model. Second, at the parameter level, a positive effect of $\beta$ would indicate that the presidency's policy position has a larger weight in determining the policy outcome. The presidency effect hypothesis $(\mathrm{H} 1)$ can now be restated more formally as follows: $\mathrm{H} 1: \beta>0$.

The model can be extended to account for the specific presidency power in different stages of the bargaining process:

$$
\log \left(\alpha_{i j}\right)=\beta_{1} P_{i j}^{\mathrm{PA}}+\beta_{2} P_{i j}^{\mathrm{A}}+\beta_{3} P_{i j}^{\mathrm{I}}+\beta_{4} P_{i j}^{\mathrm{D}}
$$

For each stage, $P_{i j}^{\mathrm{PA}}, P_{i j}^{\mathrm{A}}, P_{i j}^{\mathrm{I}}, P_{i j}^{\mathrm{D}}=1$ if member state $i$ holds the presidency in the respective stage (the pre-adoption, the adoption, the intermediate, and the final voting stage). $P_{i j}^{\mathrm{PA}}, P_{i j}^{\mathrm{A}}, P_{i j}^{\mathrm{I}}, P_{i j}^{\mathrm{D}}=0$ otherwise. 
On the basis of this model, the adoption stage presidency hypothesis (H2) can be restated as $\mathrm{H} 2: \beta_{2}>\beta_{1}, \beta_{3}$, and the voting stage presidency hypothesis (H3) as H3: $\beta_{4}>\beta_{3}$.

\section{Research design and data}

The hypotheses are tested using data on 66 legislative Commission proposals from the first pillar of EU decision-making. This 'Community' pillar covers the larger share of EU policy-making, including the Internal Market and Agriculture. The data collection was coordinated by the DEU research team and published in several contributions (e.g. Stokman and Thomson, 2004; Thomson et al., 2006). The selected proposals are a comprehensive selection of proposals that meet a number of criteria. First, the data set contains proposals that were subject to the consultation or to the co-decision procedure. Second, it contains proposals discussed in the Council in the period 1999-2000. All final decision outcomes were reached in the period 1999-2001, and the proposals did not change procedure after the Amsterdam Treaty came into effect in 1999 (with one exception that was finalized in the first term of 1998). The time that a proposal is 'pending' between adoption by the Commission and the final decision outcome varies between 3 and 68 months in the data set. Third, the proposals were selected on the basis of a certain degree of controversy. A random sample of Commission proposals would lead to an overrepresentation of relatively unimportant, technical issues on which member states take similar positions. This would reduce the ability to discriminate between powerful and less powerful actors in the decision-making process. An important condition for controversy of a proposal was that it must have appeared in Agence Europe, an independent daily news service covering EU affairs. These criteria resulted in the collection of 66 proposals covering a broad range of policy areas (Thomson et al., 2006).

For each Commission proposal, experts were asked to identify issues around which decision-making took place. An issue could be constructed if at least some of the actors have opposing positions, if the issue represents a one-dimensional continuum and if the points on the continuum represent alternative policy outcomes (Thomson and Stokman, 2003). The experts identified 162 issues within the 66 proposals. Of the 162 issues, 4 have missing values on at least one of the explanatory variables. In 6 cases, the presidency in the adoption stage is the same as the presidency in the voting stage, i.e. these issues were adopted and decided upon within one presidency term of six months. Because these few cases would (arguably) induce interaction 
effects between stages, we excluded them from the analyses. Ultimately, 152 issues nested in 61 proposals are included in the following analyses.

The dependent variable in our analyses is the policy outcome on each issue, identified by the experts and assigned a value on the policy scale. If an issue is dichotomous, the policy outcome is either one of the two policy alternatives. The independent variables in the models are actors' initially preferred policy positions, their salience and power, and a variable indicating whether a member state holds the presidency. Initially preferred policy positions and salience are also operationalized by expert judgements. Again, these are congruent with the possible policy alternatives, and salience may take any value between 0 and 100, with higher levels indicating stronger commitment to an issue by a member state.

Retrospective bias in expert judgements was reduced through several procedures (Thomson et al., 2006). First, most of the experts were closely affiliated with the permanent representations of the member states, e.g. desk officers representing their state in Council discussions. Others were affiliated with the Commission, the EP or interest groups. In total 150 interviews were held with 125 experts. These were in-depth interviews lasting for 1 hour and 40 minutes on average, to make it possible to evaluate experts' effort and expertise. Moreover, the experts were asked to consider specific policy issues rather than abstract dimensions (e.g. pro- and anti-European), which reduces the likelihood that experts use different criteria for their judgements (Budge, 2000).

Power is defined as the sum of resources that can be used by an actor to move the policy outcome on an issue towards the desired outcome. Studies on bargaining typically take formal voting power as the cornerstone in their analyses, using a voting power index. ${ }^{5}$ The Shapley-Shubik Index (SSI) figures predominantly among these: power is defined by the number of times an actor is pivotal over all permutations of the actor set (Shapley and Shubik, 1954). There are doubts about the usefulness of this index. Most importantly, it fails to take into account the preferences of the actors and the impact of certain procedural settings on power (Garrett and Tsebelis, 1999; Schneider et al., 2004). The SSI considers all permutations to be equally likely, whereas some coalitions simply cannot be formed owing to opposing preferences. The DEU data set includes SSI scores for four different procedural conditions: the co-decision procedure with either the QMV or unanimity voting rule in the Council, and the consultation procedure with either QMV or unanimity. ${ }^{6}$

The independent variable of central concern is a dummy that indicates whether a member state holds the presidency, and a series of (mutually exclusive) dummies related to the different bargaining stages. Table 1 shows the distribution of proposals and issues over the presidency terms in the DEU 
Table 1 Distribution of policy proposals and policy issues (in brackets) over presidencies and bargaining stages

\begin{tabular}{|c|c|c|c|c|c|}
\hline $\begin{array}{l}\text { Year/ } \\
\text { half }\end{array}$ & Presidency & $\begin{array}{l}\text { Development } \\
\text { stage }\end{array}$ & $\begin{array}{l}\text { Adoption } \\
\text { stage }\end{array}$ & $\begin{array}{l}\text { Intermediate } \\
\text { stage }\end{array}$ & $\begin{array}{l}\text { Voting } \\
\text { stage }\end{array}$ \\
\hline $1995-2$ & Spain & $6(17)$ & $0(0)$ & $0(0)$ & (0) \\
\hline $1996-1$ & Italy & $1(2)$ & $6(17)$ & $0(0)$ & $0(0)$ \\
\hline $1996-2$ & Ireland & $0(0)$ & $1(2)$ & $6(17)$ & $0(0)$ \\
\hline $1997-1$ & Netherlands & $2(4)$ & $0(0)$ & $7(19)$ & $0(0)$ \\
\hline 1997-2 & Luxembourg & $7(22)$ & $2(4)$ & $7(19)$ & $0(0)$ \\
\hline $1998-1$ & United Kingdom & $10(23)$ & $7(22)$ & $9(23)$ & $1(1)$ \\
\hline $1998-2$ & Austria & $8(13)$ & $10(23)$ & $15(44)$ & $0(0)$ \\
\hline $1999-1$ & Germany & $19(44)$ & $8(13)$ & $20(56)$ & $5(11)$ \\
\hline 1999-2 & Finland & $5(17)$ & $19(44)$ & $16(44)$ & $11(25)$ \\
\hline $2000-1$ & Portugal & $3(10)$ & $5(17)$ & $27(70)$ & $10(22)$ \\
\hline $2000-2$ & France & $0(0)$ & $3(10)$ & $17(50)$ & $14(33)$ \\
\hline 2001-1 & Sweden & $0(0)$ & $0(0)$ & $8(26)$ & $11(33)$ \\
\hline $2001-2$ & Belgium & $0(0)$ & $0(0)$ & $0(0)$ & $9(27)$ \\
\hline \multirow{2}{*}{\multicolumn{2}{|c|}{$\begin{array}{l}\text { Total } \\
\text { Number of member states }\end{array}$}} & $61(152)$ & $61(152)$ & $132(364)$ & $61(152)$ \\
\hline & & & & & \\
\hline \multicolumn{2}{|c|}{ holding the presidency } & 9 & 9 & 10 & 7 \\
\hline
\end{tabular}

Source: DEU data set (Thomson and Stokman, 2003).

Notes: Included are 61 selected Commission proposals discussed in the Council in the period 1999-2001.

data. The Commission adopted most proposals in the presidency terms of Austria, Finland, Germany and the United Kingdom, and most were finalized by Finland, Portugal, France, Sweden and Belgium.

\section{Results}

\section{Policy distances}

Table 2 displays a first indication of presidency power. For each member state, the mean distance over all issues is calculated between the policy position and (1) the Commission's position, (2) the weighted mean voter prediction, and (3) the actual policy outcome. The distance to the Commission gives an indication of how successful the lobbying efforts of an actor could have been. The closer a member state's policy position to the Commission's position, the more the Commission's position reflects the position of the member state. The 


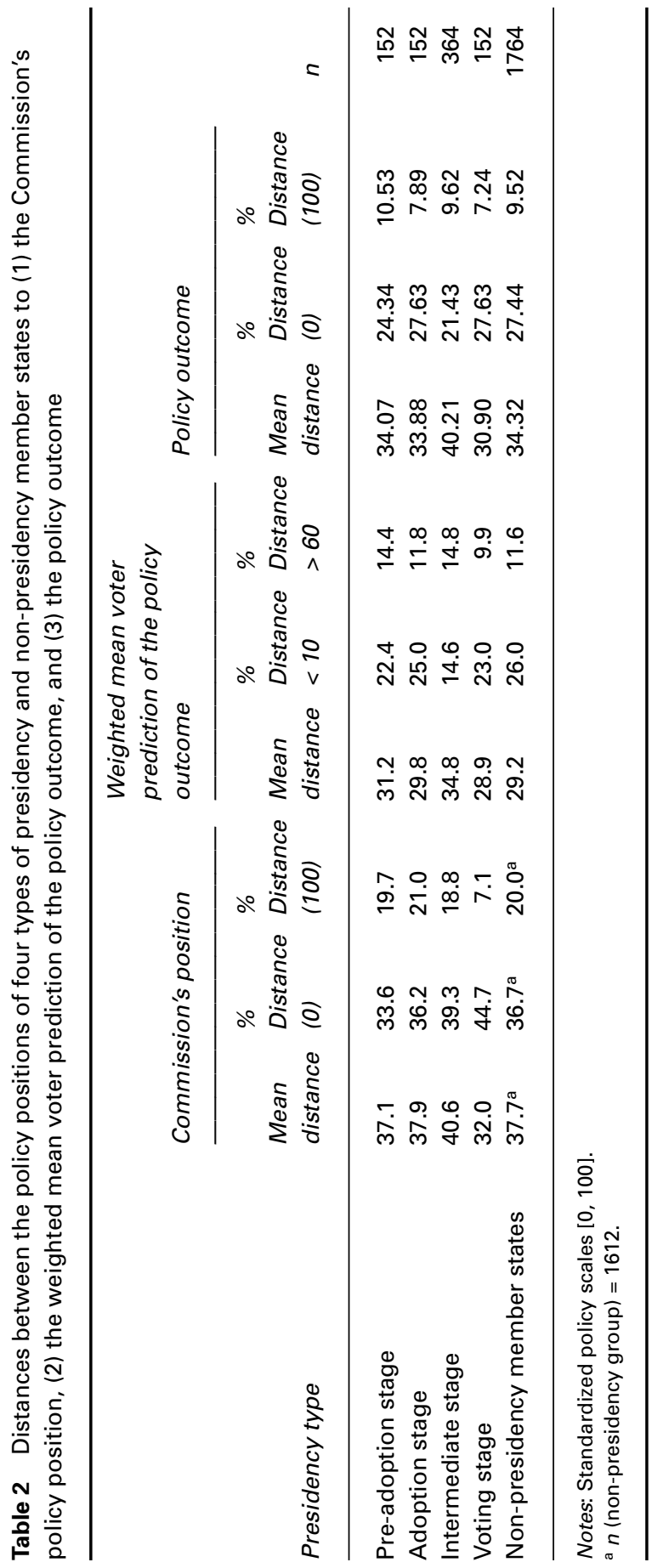


distance to the weighted mean voter prediction indicates how central an actor is in the policy space. It is useful to analyse whether presidencies in one stage or the other have more central positions in the policy space, because centrality enhances their opportunities for success (Bailer, 2004). Finally, the distance of an actor's policy position to the policy outcome is a measure of preference loss suffered from the collective outcome (Torenvlied, 1996).

There are 152 observations for each actor and 17 actors within each issue, accumulating to 2584 observations. Table 2 groups these observations according to the different bargaining stages. The mean distances are calculated for each group, excluding the 152 observations for the Commission when calculating the mean distance to the Commission's position. The percentage of observations for which the distance was minimal (0) and maximal (100) is also displayed. Distributions of distances are highly skewed: many observations have extreme values, with distances being either minimal or maximal. ${ }^{7}$

If lobbying is an important source of power for the presidency, we should observe small distances between the Commission's position and the policy positions of pre-adoption and adoption stage presidencies. Table 2 shows that this is not the case: the mean distances are not smaller compared with the mean distance of non-presidency member states. Other member states are equally likely to have their position reflected by the Commission in the preadoption and adoption stages.

Turning to the centrality of presidencies in different stages of the bargaining process, Table 2 suggests that no group of presidencies is close to the weighted mean voter prediction. The mean distances to the weighted mean voter prediction are considerable for each bargaining stage and not different from the non-presidency group of observations. Hence, we can be confident that a result of presidency power will not be an artefact of centrality in the policy space.

The mean distances to the policy outcome are an indication of the preference loss that presidencies suffer in the different bargaining stages. There are two main conclusions to be drawn here. The mean distances to the policy outcome are largest for presidencies in the intermediate stage, indicating that they are indeed less powerful than adoption and voting stage presidencies. Second, the mean distances to the policy outcome are smallest for voting stage presidencies as compared with both non-presidencies and other presidency types. This suggests that voting stage presidencies are more powerful.

\section{Parameter estimation}

We test our three hypotheses by fitting three regression models with the presidency weights as the only unknown parameter. The first regression model is 
an empty baseline model, with $\log \left(\alpha_{i j}\right)=0$, or $\alpha_{i j}=1$ for all member states in all issues. In the second regression model $\log (\alpha)$ is modelled as a function of dummy predictor $P$, indicating whether a member state holds the presidency in any stage or not at all. Thus, $\beta<0$ implies that the weight of a member state's position decreases (i.e. $\alpha=e^{(\beta)}<1$ ) when it holds the presidency in any stage (the reverse holds when $\beta>0$ ). This allows us to test the presidency effect hypothesis. In the third model, four dummy variables are entered into the regression equation, each indicating whether a member state holds the presidency in a specific stage, with $P^{\mathrm{PA}}$ for the pre-adoption stage, $P^{\mathrm{A}}$ for the adoption stage, $P^{\mathrm{I}}$ for the intermediate stage, and $P^{\mathrm{D}}$ for the voting stage. This model allows us to test the adoption and voting stage hypotheses.

The weighted mean voter model includes the parameters $\beta_{\mathrm{m}}$ in a nonlinear way. We therefore fitted the models using non-linear regression techniques with maximum likelihood estimation. Issues are nested in proposals, and thus we adjusted for the clustering of issues in proposals with the cluster-adjusted sandwich estimates of variance (Rogers, 1993). This clustering makes the log-likelihood tests for model comparison inappropriate, since they no longer follow a chi-squared distribution. Hence, we use the Wald test for model comparison, based on the estimated standard error of the residuals. Although not a strong statistical test, a large reduction in the standard error of the residuals implies a better fit of the model. Additionally, we examine the mean errors of the predictions to evaluate the relative accuracy of the models.

Table 3 reports the exponents of the regression parameters of the three models. These exponents represent the number by which the weight of a member state's position is multiplied in the specific model. The baseline mean voter model reproduces the results found by Thomson et al. (2006). They report a mean absolute error of 23. We find a mean error of 23.2 and this results from a slight difference in the number of issues (Thomson et al., 2006, used 162).

The presidency model contains a parameter for holding the presidency anywhere in the bargaining process $(P)$, and provides a direct test of the presidency effect hypothesis. The parameter is larger than 1, which means that there is additional presidency power, but the effect is not significant. Overall, presidencies do not seem to realize policy outcomes closer to their preferred position than 'ordinary' member states do. The mean error of the predictions is 0.1 point larger than the mean error of the baseline model, indicating a slight reduction in model accuracy.

When we move our analysis to presidencies in different bargaining stages, we observe that voting stage presidencies are significantly more powerful than non-presidency member states. The size of the effect is 
Table 3 Non-linear regression analysis of policy outcomes discussed in the Council in the period 1999-2001

\begin{tabular}{|c|c|c|c|}
\hline Variable & $\begin{array}{l}\text { Baseline } \\
\text { model }\end{array}$ & $\begin{array}{l}\text { Presidency } \\
\text { model } \\
e^{(\beta)}\end{array}$ & $\begin{array}{l}\text { Presidency stage } \\
\text { model } \\
e^{(\beta)}\end{array}$ \\
\hline \multicolumn{4}{|l|}{ Presidencies } \\
\hline Presidency $(P)$ & & $\begin{array}{l}1.84 \\
(.75)\end{array}$ & \\
\hline Pre-adoption stage ( $\left.P^{\mathrm{PA}}\right)$ & & & $\begin{array}{l}1.35 \\
(.20)\end{array}$ \\
\hline Adoption stage $\left(P^{A}\right)$ & & & $\begin{array}{l}1.12 \\
(.04)\end{array}$ \\
\hline Intermediate stage $\left(P^{\prime}\right)$ & & & $\begin{array}{l}1.65 \\
(.75)\end{array}$ \\
\hline Voting stage $\left(P^{D}\right)$ & & & $\begin{array}{l}4.88^{* * * *} \\
(1.79)\end{array}$ \\
\hline Standard deviation of residuals & 30.97 & 30.88 & 30.57 \\
\hline Wald test & & 1.79 & $10.31 * *$ \\
\hline Mean error & 23.2 & 23.3 & 22.8 \\
\hline$N^{\mathrm{a}}$ & 152 & 152 & 152 \\
\hline \multicolumn{4}{|c|}{$\begin{array}{l}\text { Notes: Sandwich estimates for standard errors, adjusted for clustering of issues in proposals; } \\
\text { exponents of parameters and standard errors reported. } \\
\text { a } 152 \text { policy issues are nested in } 61 \text { Commission proposals. } \\
{ }^{*} p<.10 ;{ }^{* *} p<.05 ;{ }^{* * *} p<.01 \text { (two-sided). }\end{array}$} \\
\hline
\end{tabular}

considerable. The SSI scores have a range of [0,1], and a multiplication of this weight by 4.88 is impressive. The voting stage presidency hypothesis is thus strongly corroborated. Adoption stage presidencies, on the other hand, are not significantly more powerful than pre-adoption stage and intermediate stage presidencies. Thus, the adoption stage presidency hypothesis needs to be rejected. The weights for presidencies in the first stages of the bargaining process do not differ from those for ordinary member states in those stages. This is confirmed by testing the joint significance of the parameters for the first three stages $\left(\chi^{2}(\mathrm{df}=3)=1.57, p=.67\right)$. Overall, model predictions are not much more accurate than the baseline predictions. The mean error decreases by 0.4 . Thus, the inclusion of presidency power parameters only marginally reduces the model errors.

We performed a number of additional analyses to check whether the presidency effects found in the presidency stage model remain stable if we include more complex assumptions about the mechanisms underlying presidency 
power. First, we investigated for all bargaining stages whether the presidency's power is affected by the degree of salience. Considering the limited amount of time available to a presidency, it can be expected to mobilize its resources specifically on those issues that are more salient. We included parameters for interaction effects between all presidencies and their level of salience. Initially, we found a positive and significant interaction effect for voting stage presidencies $\left(e^{(\beta)}=1.06, p=.09\right)$, meaning that, as salience increases, power increases. However, the effect is oddly large and significant only at the .10 level, probably owing to estimation problems. Including only the interaction for voting stage presidencies yielded non-significant results.

Furthermore, we tested whether it is the powerful member states that are responsible for an increase in power when they become President. For all stages we included an interaction effect with the voting weight $\left(w_{i j}\right)$. If presidency power increases as voting power increases, we would conclude that powerful member states in particular benefit from holding the presidency office. The opposite may also be true, since powerful member states could be watched more closely by other member states when they hold the presidency. None of the interaction effects for the different bargaining stages were significant.

Finally, we tested whether the distance between the policy position of the President and the Commission's position affects the power of presidencies in the pre-adoption and adoption bargaining stages. The power of adoption stage presidencies does not increase or decrease as a result of an increase in the distance to the Commission's position $\left(e^{(\beta)}=.97, p=.44\right)$, nor does the power of pre-adoption stage presidencies $\left(e^{(\beta)}=1.05, p=.21\right)$. We thus conclude that agreement with the Commission does not reinforce the effects of presidency power. ${ }^{8}$

We also tested for the robustness of our results. This is important, considering the limitations of the data set in terms of the available distribution of presidencies over the selected issues and the limited time frame of the study. It could well be the case that, coincidentally, some tough issues were assigned to a specific presidency. It could also be the case that idiosyncrasies of specific presidencies, for example the personality of the political leader, affected bargaining power rather than the institution of the presidency. Tests for the amount of unexplained variance at the member state level run into identification problems, as well as regressions that include control variables at the member state level. Consequently, we used a more informal test for robustness: we fitted the presidency stage model seven times, each time excluding all issues under the presidency term of one of the seven member states in the voting stage. Most conspicuously, the voting stage presidency effect increases from $4.88(p<.01 ; n=152)$ to $7.02(p<.005 ; n=119)$ when 
the 33 issues for France are excluded. Excluding the issues for the other voting stage presidencies yielded small increases in power in all cases. Only excluding the 33 issues for Sweden yielded a decrease in power for voting stage presidencies from $4.88(p<.01 ; n=152)$ to $2.48(p=.31 ; n=119)$. Apparently, Sweden was a highly effective voting stage presidency, whereas France was the least effective for the Council decisions under study.

We ran a number of other checks for robustness of our results. First, we repeated the model estimations for the presidency stage model 61 times, leaving one proposal out of the analysis each time, to test for outliers and idiosyncrasies of issues. This did not change the results. We excluded dichotomous issues from the regression analyses because these would arguably violate assumptions of normality and continuous dependent variables. Parameters did not change significance, except for the pre-adoption stage presidencies, whose parameter became significant although smaller than for voting stage presidencies $\left(e^{(\beta)}=3.47, p<.05\right)$. The mean errors of all models decreased. ${ }^{9}$ Finally, we used an expert-assigned power score of the member states as an alternative to the SSI power indices. The same results were obtained for all parameters.

\section{Discussion and conclusion}

In this paper, we have made a first attempt to examine the power of the presidency of the Council of the European Union using a large-scale quantitative data set. We tested presidency effects on policy outcomes using a cooperative bargaining model of decision-making. It proved useful to discriminate between the power of presidencies at different stages of the bargaining process. We partly rejected the view of the 'toothless' presidency. We were able to show that it does not pay to hold the presidency in the earlier stages of bargaining, when decentralized lobbying is the prominent way of exerting influence on policy outcomes. Instead, our analysis showed that presidencies in the more centralized voting stage can leave a domestic mark on EU policy outcomes. Independent of country size and economic power - on which formal voting power is based - presidencies in the voting stage have additional leverage in EU decision-making compared with other member states.

Our conclusions should be seen as a starting point in understanding the effects of the EU presidency. Some shortcomings in the data and analysis must be taken into account. Most importantly, the sample of Commission proposals is a selected sample. Statistical generalization to decision-making in the first pillar is not possible. Furthermore, the selection implies that 
Commission proposals reached a final decision in the period 1999-2001, thereby disregarding those proposals that were never finalized. We do not know anything about the number of proposals that never became legislation and the distribution of these proposals over presidencies. This is of major concern because agenda exclusion could be an important power tool for presidencies. If many proposals never become adopted, we may have underestimated the power of adoption stage presidencies vis-à-vis presidencies in later bargaining stages. ${ }^{10}$

There are a few more reasons to believe that the additional power of presidencies we found is a conservative estimate. First, the DEU data set includes proposals only in the first pillar of EU decision-making. One may argue that in the pillars of Common Foreign and Security Policy and Justice and Home Affairs the presidency has more opportunities to influence policy outcomes - particularly because it enjoys formal agenda-setting power (Hix, 2005). Second, if EU bargaining is characterized less by cooperation and more by tough, non-cooperative bargaining, the presidency can be expected to employ its procedural and informational advantages with even more success. Thus, we have confidence that the presidency effect we report here is a genuine characteristic of EU policy-making.

But the problem remains of confounding factors that might exist at the level of the member state. Size, experience, informal reputation in the Council, level of preparation of the presidency term, or even the personality of political leaders could all account for the effects we found. A proper test for the existence of such effects would require larger, longitudinal data sets that also incorporate precise information about the agenda-setting process. That would be the avenue for further quantitative research.

\section{Notes}

We thank three anonymous reviewers for their useful suggestions and comments.

1 The six-month rotation system was confirmed until 2006. After the Finnish presidency in the second half of 2006, a rotating 'team presidency' consisting of three member states will preside over the Council for 1.5 years.

2 In the data set we find an overlapping presidency for only one case.

3 Indeed, empirical studies confirm the absence of stable coalitions in the EU (Thomson et al., 2004) that could consistently beat other member states. Moreover, a cooperative (weighted mean voter) bargaining model has been tested on the DEU data before and has been found to give the most accurate predictions evaluated against a range of other cooperative and noncooperative decision models (Thomson et al., 2006). For inclusive decision rules, the weighted mean is a better predictor in comparison with the median. 
Thomson and Torenvlied (2005) tested the predictions of the mean and median voter models over a large pooled data set of controversial issues with an over-sample of DEU issues - in various political settings. They found that, when the decision rule is qualified majority voting (QMV), the simple mean is the best predictor, whereas under unanimity the mean weighted by the power and salience of the actors performs best. Since all decision-making in the EU is subject to either QMV or unanimity, the (weighted) mean seems to be appropriate.

4 The mean voter position weighted by actors' capabilities and salience was first used in an empirical analysis of EU decision-making by Van den Bos (1991).

5 For an overview of some applications using voting power indices, see Felsenthal and Machover (1995). An application on EU decision-making is Kandogan (2000).

6 The Commission is always included as a member of the winning coalition under both the co-decision and the consultation procedures. Under codecision with QMV voting in the Council, the winning coalition consists of the Commission, a qualified majority of member states and the EP. Under consultation with QMV voting in the Council, the winning coalition consists of the Commission and a qualified majority of member states. In effect, the Parliament's power is zero under consultation, and the Commission's power is largest under QMV in the Council. We emphasize that the approach here would in principle allow us to treat the power $w_{i}$ of the member states as parameters to be estimated, rather than to be assumed by SSI. Since the amount of data that we have is limited, we abstained from this method.

7 This is mainly owing to the inclusion of dichotomous issues.

8 Table 2 also showed that the distance of voting stage presidencies to the Commission's position was smaller compared with non-presidencies. Adding an interaction parameter for the voting stage to the presidency stage model, however, also did not show significant results $\left(e^{(\beta)}=1.02, p=.13\right)$.

9 For the baseline, presidency and presidency stage models the mean errors were $20.65,20.25$ and 19.80 respectively. The presidency stage model is still a significant improvement on the baseline model (Wald $(4)=20.25, p<.001$ ).

10 This is also under the assumption that the presidency's policy positions on the issues in these proposals are far away from the expected policy outcome.

\section{References}

Achen, Christopher (2006) 'Institutional Realism and Bargaining Models', in Robert Thomson, Frans N. Stokman, Christopher Achen and Thomas König (eds) The European Union Decides. Cambridge: Cambridge University Press.

Arregui, Javier, Frans N. Stokman and Robert Thomson (2004) 'Bargaining in the European Union and Shifts in Actors' Policy Positions', European Union Politics 5(1):47-72.

Aspinwall, Mark and Gerald Schneider (2000) 'Same Table, Separate Menu: The Institutionalist Turn in Political Science and the Study of European Integration', European Journal of Political Research 38:1-36. 
Bailer, Stephanie (2004) 'Bargaining Success in the European Union: The Impact of Exogenous and Endogenous Power Resources', European Union Politics 5: 99-123.

Bassompierre, Guy de (1988) Changing the Guard in Brussels: An Insider's View of the EC Presidency. New York: Praeger.

Bindseil, U. and C. Hantke (1997) 'The Power Distribution in Decision-Making among EU Member States', European Journal of Political Economy 13(1): 171-85.

Budge, Ian (2000) 'Expert Judgements of Party Policy Positions: Uses and Limitations in Political Research', European Journal of Political Research 37(1): 103-13.

Bueno de Mesquita, Bruce and Frans N. Stokman (eds) (1994) European Community Decision Making: Models, Applications, and Comparisons. New Haven, CT: Yale University Press.

Caplin, Andrew and Barry Nalebuff (1991) 'Aggregation and Imperfect Competition: On the Existence of Equilibrium', Econometrica 59: 1-23.

Cini, Michelle (1996) The European Commission: Leadership, Organisation and Culture in the EU Administration. Manchester: Manchester University Press.

Crombez, Christopher (2000) 'Institutional Reform and Co-Decision in the European Union', Constitutional Political Economy 11: 41-57.

Fearon, James D. (1988) 'Bargaining, Enforcement, and International Cooperation', International Organization 52(2): 269-305.

Felsenthal, Dan S. and Moshé Machover (1995) 'Postulates and Paradoxes of Relative Voting Power - A Critical Re-appraisal', Theory and Decision 38: 195-229.

Garrett, Geoffrey and George Tsebelis (1999) 'Why Resist the Temptation to Apply Power Indices to the European Union?', Journal of Theoretical Politics 11(3): 291-308.

Hayes-Renshaw, Fiona and Helen Wallace (1997) The Council of Ministers. New York: St. Martin's.

Hix, Simon (2005) The Political System of the European Union, 2nd edn. London: Macmillan.

Kandogan, Yener (2000) 'Political Economy of the Eastern Enlargement of the European Union: Budgetary Costs and Reforms in Voting Rules', European Journal of Political Economy 16(4): 685-705.

Kirchner, Emile J. (1992) Decision-making in the European Community: The Council Presidency and European Integration. Manchester: Manchester University Press.

Lootsma, Freerk A. (2004) 'Assignment of Weights to the Member States of the European Union in Order to Model Their Relative Power Positions', Group Decision and Negotiation 13: 301-13.

Mattila, Mikko and Jan-Erik Lane (2001) 'Why Unanimity in the Council? A Roll Call Analysis of Council Voting', European Union Politics 2(1): 31-52.

Nash, John F. (1950) 'Equilibrium Points in N-Person Games', Proceedings of the National Academy of Sciences of the United States of America 36: 48-9.

Nicoll, William (1998) 'The Budget Council', in Martin Westlake (ed.) The Council of the European Union, 2nd edn, pp. 179-90. London: John Harper.

Rogers, William H. (1993) 'Regression Standard Errors in Clustered Samples', Stata Technical Bulletin 13: 19-23.

Scharpf, Fritz W. (1988) 'The Joint-Decision Trap: Lessons from German Federalism and European Integration', Public Administration 66: 239-78. 
Schneider, Gerald, Daniel Finke and Stefanie Bailer (2004) 'Bargaining Power in the European Union: An Evaluation of Competing Game-Theoretic Models', paper prepared for presentation at the annual meeting of the International Studies Association, Montreal, Canada, 17-20 March.

Schout, Adriaan (1998) 'The Presidency as Juggler: Managing Conflicting Expectations', Eipascope 2: 2-10.

Selck, Torsten J. and Bernard Steunenberg (2004) 'Between Power and Luck: The European Parliament in the EU Legislative Process', European Union Politics 5(1): 25-46.

Shapley, Lloyd S. and Martin Shubik (1954) 'A Method for Evaluating the Distribution of Power in a Committee System', American Political Science Review 48(3): 787-92.

Shepsle, K.A. (1989) 'Studying Institutions: Some Lessons from the Rational Choice Approach', Journal of Theoretical Politics 1(1): 131-47.

Sherrington, Philippa (2000) The Council of Ministers: Political Authority in the European Union. London: Pinter.

Stokman, Frans N. and Robert Thomson (2004) 'Winners and Losers in the European Union', European Union Politics 5(1): 5-23.

Tallberg, Jonas (2003) 'The Agenda-Shaping Powers of the EU Council Presidency', Journal of European Public Policy 10(1): 1-19.

Tallberg, Jonas (2006) Leadership and Negotiation in the European Union. Cambridge: Cambridge University Press.

Thomson, Robert and Frans N. Stokman (2003) Decision Making in the European Union [machine readable data set]. Groningen: ICS.

Thomson, Robert and René Torenvlied (2005) 'A Test of the Accuracy of the Median and Mean Voters' Positions as Predictions of Decision Outcomes Using a Pooled Dataset', Mimeo, Utrecht University.

Thomson, Robert, Jovanka Boerefijn and Frans N. Stokman (2004) 'Actor Alignments in European Union Decision-making', European Journal of Political Research 43(2): 237-61.

Thomson, Robert, Frans N. Stokman, Christopher Achen and Thomas Koenig (eds) (2006) The European Union Decides. Cambridge: Cambridge University Press.

Torenvlied, René (1996) 'Political Control of Implementation Agencies: Effects of Political Consensus on Agency Compliance', Rationality and Society 8: 25-56.

Torenvlied, René (2000) Political Decisions and Agency Performance. Boston: Kluwer Academic.

Tsebelis, George and Geoffrey Garrett (2000) 'Legislative Politics in the European Union', European Union Politics 1(1): 9-36.

Van den Bos, Jan M. (1991) Dutch EC Policy Making: A Model-Guided Approach to Coordination and Negotiation. Amsterdam: Thela Thesis.

Van Schendelen, M.C.P.M. (1996) 'The Council Decides: Does the Council Decide?', Journal of Common Market Studies 34: 531-48.

Wallace, Helen and William Wallace (2000) Policy-Making in the European Union, 4th edn. Oxford: Oxford University Press.

Westlake, Martin (1995) The Council of the European Union. London: Cartermill. 


\section{About the authors}

Jelmer Schalk is a graduate student in the Department of Sociology, Utrecht University, Heidelberglaan 1, 3584 CS, Utrecht, The Netherlands. Fax: +31302534405

E-mail: J.Schalk@uu.nl

René Torenvlied is Associate Professor, Department of Sociology, Utrecht University, Heidelberglaan 1, 3584 CS, Utrecht, The Netherlands. Fax: +31302534405

E-mail: R.Torenvlied@fss.uu.nl

Jeroen Weesie is Associate Professor, Department of Sociology, Utrecht University, Heidelberglaan 1, 3584 CS, Utrecht, The Netherlands. Fax: +31302534405

E-mail: J.Weesie@fss.uu.nl

Frans Stokman is Professor, Department of Sociology, University of Groningen, Grote Rozenstraat 31, 9712 TG Groningen, The Netherlands. Fax: +31503636226

E-mail: F.N.Stokman@rug.nl 